\title{
Educação de jovens e adultos: ensinar e aprender sob a perspectiva de Paulo Freire
}

Sônia Ferreira de Jesús ${ }^{1}$, Moabe Vieira²

\begin{abstract}
Resumo
Este trabalho é resultado de pesquisas bibliográficas sobre alfabetização de jovens e adultos e tem como objetivo refletir sobre como estão sendo efetivadas as práticas metodológicas com esse grupo em fase de alfabetização e mostrar os pressupostos teóricos de Paulo Freire, em se tratando do ensino e aprendizagem nessa faixa etária, que conduz a uma educação libertadora. Inicialmente, o texto aborda as características dessa clientela escolar. Em seguida, é feita uma exposição sobre métodos e práticas de alfabetização realizadas, atualmente, com esses educandos, não condizentes com uma educação transformadora. Por fim, traz as propostas metodológicas idealizadas por Paulo Freire para a alfabetização nessa idade. A temática em questão já é ressaltada em pesquisas no âmbito da educação popular, porém a abrangência de investigações nessa área se faz necessária, tendo em vista ampliar saberes e clarificar a visão dos educadores para a realidade atual. A finalidade desta investigação é propor mudanças nas concepções de ensino e aprendizagem já arraigadas no pensamento dos trabalhadores da educação, em todos os níveis de ensino, mais precisamente nos que atuam na educação de jovens e adultos (EJA). O estudo mostrou a possibilidade de realizar um trabalho diferenciado, levando-se em conta as características do aluno adulto, articulando o ensino com suas vivências e contexto de atividades pessoais, profissionais e escolares.
\end{abstract}

\section{Palavras-chave}

EJA. Alfabetização. Ensino-Aprendizagem. Paulo Freire.

1. Mestranda em Educação na Universidade Federal de Uberlândia, pedagoga no Instituto Federal de Educação, Ciência e Tecnologia de Goiás (Campus Itumbiara). E-mail: soniaferreiradejesus@gmail.com.

2. Especialista em Psicopedagogia Escolar pela Universidade Federal de Uberlândia, educadora infantil na rede municipal de ensino de Uberlândia-MG. E-mail: moabe.vieira@yahoo.com.br. 


\title{
Youth and adult education: teaching and learning from Paulo Freire's perspective
}

Sônia Ferreira de Jesús*, Moabe Vieira**

\begin{abstract}
This work is the result of a bibliographic research on youth and adult literacy. It aims to bring a reflection on how methodological practices with this specific group are being adopted and to show Paulo Freire's theoretical framework of youth and adult education, which leads to a liberating education. First, this text provides an approach to the characteristics of this specific group of students. Second, it introduces the literacy methods and practices used today with these students, which are not suitable for a transformative learning. Finally, it brings up methodological proposals idealized by Paulo Freire for adult and youth learning. This theme has already been explored by popular education researches, however, it is necessary to increase the scope of the research in this area of knowledge in order to broaden knowledge and make educator aware of the current reality. The purpose of this research is to propose changes in the teaching and learning conceptions that are entrenched in the educators' thoughts in every levels of education, but specifically in youth and adult education. The study has showed the possibility of educating in a different way by taking into account the characteristics of the adult learners, articulating learning with their experiences and their personal, scholar and professional activity context.
\end{abstract}

\section{Keywords}

Youth and Adult Education. Literacy. Education. Learning. Paulo Freire.

\footnotetext{
* MSc student in Education, Federal University of Uberlândia, State of Minas Gerais, Brazil; professor, Education, Science and Tecnology Federal Institute of Goiás (Campus Itumbiara), State of Goiás, Brazil. E-mail: soniaferreiradejesus@gmail.com.

* Specialist in School Educational Psychology, Federal University of Uberlandia, State of Minas Gerais, Brazil; early childhood teacher at municipal education system, Uberlândia, State of Minas Gerais, Brazil. E-mail: moabe. vieira@yahoo.com.br.
} 


\section{Introdução}

A Educação de Jovens e Adultos (EJA) atende a uma enorme parcela da população. Pessoas que não tiveram oportunidade de estudar na época certa por falta de tempo, por terem tido outras necessidades mais urgentes ou, ainda, por problemas que enfrentaram durante o início da alfabetização, gerando o fracasso e a evasão escolar. Aliar o trabalho com os estudos, por vezes, é um entrave para alguns, o que traz, como consequência, a saída da escola. Outros aspectos, como os familiares, gravidez precoce, envolvimento com drogas, desmotivação, dentre outros, também podem ser as causas do abandono dos estudos.

A história da EJA é marcada por movimentos que procuraram suprir as necessidades políticas e educacionais de um grupo que vivenciava uma injustiça social representada pelo analfabetismo. Os estudantes da EJA são, em sua maioria, trabalhadores ou mesmo donas de casa que sentiram a necessidade de voltar à escola, não somente para aprender a ler e escrever, mas para dar continuidade aos estudos. Muitos também se inserem em classes alfabetizadoras por terem consciência de que sua integração e inserção no mercado de trabalho dependem do acesso à instrução.

Há de se considerar que esses estudantes chegam à sala de aula após um dia cansativo de trabalho, carregados de saberes cotidianos, e que eles veem na EJA uma oportunidade de suprir uma falta que os impede de serem vistos em igualdade para com os outros, nas relações pessoais e/ou de trabalho.

Nessa área da educação, há vários problemas que impedem $\mathrm{o}$ adulto de aprender. Um deles é o tipo de trabalho desenvolvido sobre um processo pedagógico construído com base na escolaridade para crianças. É preciso, então, repensar a EJA sob a visão de uma prática pedagógica diferenciada em sala de aula, levando-se em conta o educando com suas peculiaridades.

A pesquisa pode ser o início de um trabalho inovador de alfabetização de adultos, realizado no coletivo, considerando as vivências locais e regionais dos educandos. Para Brandão (1981), essa pesquisa não parte do pressuposto de uma investigação científica, mas de algo criativo, viabilizando a descoberta da vida por meio da fala e do mundo através da palavra. O conjunto de material, criado com desenhos, palavras, frases e fotos, será um suporte em benefício da aprendizagem, em que o universo investigativo é o mundo de contexto.

\section{Alfabetização, métodos e práticas na EJA}

O que se percebe, atualmente, é a alfabetização do adulto com métodos que não têm relação alguma com as necessidades desses educandos. Essa colocação é reforçada por Brandão (1981, p. 10), na seguinte fala:

Métodos de alfabetização têm um material pronto: cartazes, cartilhas, cadernos de exercício. Quanto mais o alfabetizador acredita que aprender é enfiar o saber-dequem-sabe no suposto vazio-de-quem-nãosabe, tanto mais tudo é feito de longe e chega pronto, previsto. Paulo Freire pensou que um método de educação construído em cima da ideia de um diálogo entre educador e educando, onde há sempre partes de cada um no outro, não poderia começar com o educador trazendo pronto, do seu mundo, do seu saber, o seu método e o material da fala dele.

Muitas escolas permanecem com o ensino da leitura e da escrita nos moldes de um processo ensino-aprendizagem com abordagem tradicional, em que o professor é o transmissor do conteúdo e o aluno é passivo 
de informações. Mais preocupante que isso são os métodos utilizados para alfabetizar, muito próximos daqueles que ocorrem em salas de educação infantil e ensino fundamental, ou seja, da mesma forma que alfabetizam uma criança, alfabetizam o adulto, sem levar em conta que se trata de clientelas escolares diferentes.

Brandão (1981) alerta, ainda, que as cartilhas e livros de leituras feitas especificamente para a educação de adultos com a finalidade de alfabetização traduzem um pensar pelo alfabetizando. Além disso, o autor fala da cartilha como algo pronto e imposto.

No mais, o que se pode notar, hoje, é um quadro alfabetizador descaracterizado, tradicionalista, com mecanização de tarefas e atividades e memorização incessante, no qual o aprendizado real não acontece. Os educadores, então, devem contradizer os métodos de alfabetização puramente mecânicos e ir ao encontro da alfabetização direta, levando em consideração a democratização da cultura, haja vista o fato de o EJA ser composto, em sua maioria, por trabalhadores. Portanto, oferecer material inerente à forma de vida deles é primordial para o sucesso da aprendizagem.

No entanto, o reconhecimento da educação de jovens e adultos não foi eficaz para superar os problemas da escolarização da grande parcela da população, ocasionando visões ideológicas que defendiam dois paradigmas: o da educação permanente e o da educação popular. (RIBEIRO et al., 1992).

A educação permanente tem, no adulto,

um objeto a serviço dos planos globais de desenvolvimento, através dos planos setoriais de educação. $\mathrm{O}$ educando adulto, pensado como mão de obra, estaria a serviço de um projeto mais global de sociedade, no qual, dado seu caráter autoritário, pouco poderá intervir e opinar. (RIBEIRO et al., 1992, p. 13).

Alguns modelos de educação de adultos incorporam essa concepção, negando a contribuição e o interesse do educando não escolarizado, sujeito a uma adaptação acrítica ao modelo de desenvolvimento. $\mathrm{Na}$ concepção de educação popular, com embasamento no pensamento de Paulo Freire, a educação é percebida como

prática social que tem uma dimensão pedagógica ao mesmo tempo que uma dimensão política, [...] está preocupada não com a adaptação do adulto ao modelo de desenvolvimento proposto, mas com o desenvolvimento de sua capacidade crítica, de maneira a se constituir em elemento impulsionador da sua participação na construção dos próprios projetos políticos. (RIBEIRO et al., 1992, p. 14).

Esse modelo de educação visa à participação de educadores e educandos em uma ação coletiva, na qual ambos participam do ato de ensinar-aprender. Conforme Ribeiro et al. (1992, p.14)

O educando constrói conhecimentos, independente do processo escolar, e se utiliza destes conhecimentos no ato educativo.

\section{O ensino na EJA na visão de Paulo Freire}

O "Método Paulo Freire" foi um marco de repercussão nacional e internacional, por se tratar de uma concepção geral de educação e sociedade. Paulo Freire é uma referência, "principalmente quanto à educação de adultos, ao propor uma nova prática, para a construção de uma nova sociedade" (PALANDRÉ, 2002, p. 36). O método representa um caminho a percorrer e pode ser reinventado a partir das práticas e dos contextos. Não há de se impor formas únicas, mas inovar cotidianamente para o ensino das primeiras letras, palavras e frases, tendo, como fim, o educando alfabetizado dentro do seu universo vocabular. 
A educação que Paulo Freire vislumbra não é apenas politicamente utilitária. Ela não objetiva somente criar novos quadros para um novo tipo de sociedade. Há uma proposta politicamente mais humana, a de criar, com o poder do saber do homem libertado, um homem novo, livre também de dentro para fora. O método é instrumento de preparação de pessoas para uma tarefa coletiva de reconstrução nacional. Uma nova prática, que estaria firmada antes de tudo, na leitura do mundo. Para o educando, aprender a ler e a escrever seria necessário primeiro fazer a leitura do mundo, para expressar suas ideias sobre a realidade e a cultura na qual estava inserido. O diálogo entre o professor e aluno serviria como ponto para o início de atividades em um círculo de cultura para aprofundar as leituras do mundo, e possibilitar a releitura da realidade. (BRANDÃO, 1981, p. 52).

Como visto, a educação é concebida como um ato de amor e não algo imposto. Nesse sentido, é proposto o Círculo de Cultura, como encontro presencial de sujeitos com seus saberes, histórias de vida e lugar; como o espaço de aprendizagem mais apropriado para o exercício de iniciação da dialogicidade entre indivíduos. Paulo Freire (1989) também ensina que a educação deve ser um ato coletivo, solidário e deve assumir um caráter estreitamente vinculado à realidade.

Esses Círculos, então, servem para provocar as falas espontâneas, as conversas e as trocas de experiências que fazem emergir os temas e os assuntos da vida das pessoas, temas estes propiciadores da aprendizagem significativa e simultânea para além da simples memorização de letras, sílabas e palavras. Estudar é e pode ser um momento de satisfação, tendo em vista um novo formato, no qual todos participam ativamente do processo, tanto educador e educando, numa proposta colaborativa e dialógica. É certo afirmar a importância de não somente alfabetizar, mas levar o indivíduo a ser participante do processo de ensino-aprendizagem, a compreender expressões escritas, a fazer relações da escrita com a fala e com o real.

Freire fala sobre a importância do ato de ler com compreensão crítica, um ato que não se esgota na decodificação da palavra escrita, mas que é algo que vem depois da leitura do mundo. Então, para ele, a "leitura do mundo precede a leitura da palavra" (FREIRE, 1989, p. 15).

Nesse sentido, ele nos faz pensar e refletir sobre a necessidade de levar o educando a entender as relações que permeiam a leitura e a escrita com o mundo vivido. De acordo com Freire (1989, p. 11),

a compreensão do texto a ser alcançada por sua leitura crítica implica a percepção das relações entre o texto e o contexto.

Assim, é possível entender porque muitos educandos não conseguem compreender textos, pois foram inseridos no mundo da escrita e da leitura de uma forma descontextualizada eapenas aprenderam a codificar e a decodificar por meio da memorização de letras, sílabas e palavras.

Freire (1980, p. 20) ensina sobre o universo vocabular dos grupos populares e discorre que, para se organizar o programa de alfabetização, as palavras

deveriam vir do universo vocabular dos grupos
populares, expressando a sua real linguagem,
os seus anseios, as suas inquietações, as suas
reivindicações, os seus sonhos. Deveriam vir
carregadas da significação de suas experiências
existencial e não da experiência do educador.

Ao mencionar Paulo Freire em seu estudo, Palandré (2002) também expõe que o ler e o escrever não significavam apenas codificar e decodificar palavras e frases, mas um ato que possibilita ao sujeito ser consciente, produtor de cultura e agente do mundo. As habilidades de leitura e escrita são utilizadas conforme o contexto, com a pretensão de 
conscientizar o sujeito. O próprio analfabeto

possui conhecimentos provenientes de seu observar, sentir, experimentar, vivenciar o cotidiano, e eles são imprescindíveis para a compreensão da linguagem escrita. (PALANDRÉ, 2002, p. 210).

Reafirmando essas palavras, Piconez (2002, p. 69) considera que

A idade adulta não pode ser concebida como algo estável. As experiências culturais, históricas e sociais, bem como as experiências particulares, estão relacionadas com situações de aprendizagem. O conhecimento resulta de processos de interação em diferentes contextos sociais e não em diferentes potenciais cognitivos.

Freire (1980) fala sobre a procura de uma metodologia que seja instrumento do educando e não somente do educador. Foi assim que pensou nas palavras geradoras para alfabetizar com conscientização. Para ele,

não só se retém as palavras mais carregadas de sentido existencial... senão também as expressões ligadas à experiência típicas do povo: forma de falar particulares, palavras ligadas à experiência do grupo, especialmente a experiência profissional. (FREIRE, 1980, p. 42).

Quando o educador se propõe a trabalhar didaticamente sobre essa ótica, é possível ter uma experiência enriquecedora. Nessa relação estabelecida por meio do diálogo, na busca de palavras por meio das expressões dos próprios alunos, o que emerge não se limita apenas a uma melhor forma de ensinar a ler e a escrever, mas se permite conhecer os sujeitos, saber das suas vivências, anseios e possibilidades. Freire (1980) argumenta que as palavras geradoras devem nascer dessa procura, e não na seleção que efetivamos no nosso gabinete de trabalho, por mais perfeita que ela seja do ponto de vista técnico. Diz, ainda, que, para se efetivar um trabalho de alfabetização promissor, alguns critérios na escolha de palavras devem se considerados: as dificuldades fonéticas da língua e em ordem crescente; que elas estejam dentro da realidade social, cultural e política do aluno; que tenham poder de conscientização. Além disso, devem ser propostas situações desafiadoras aos grupos de alfabetizandos e situações problemas para que eles tenham condições de chegar às suas conclusões em relação à escrita.

No enfoque dado por Freire (1987), as palavras geradoras podem ser trabalhadas no início da alfabetização; para a pós-alfabetização, são propostas atividades com temas geradores:

se, na etapa da alfabetização, a educação problematizadora e da comunicação busca e investiga a "palavra-geradora", na pósalfabetização, busca e investiga o tema gerador. (FREIRE, 1987, p. 59).

O universo vocabular do educando, a codificação, a decodificação e a problematização são categorias de conhecimento da metodologia de alfabetização freiriana, que Palandré (2002, p. 46) descreve como ponto de partida para o processo de aprender a ler e a escrever

o diálogo entre educador e os educandos, visando à compreensão do significado social dos temas em discussão e à tomada de consciência da realidade; e a problematizaçãoação e reflexão sobre a realidade [...] é a passagem de uma visão mágica para uma visão crítica do contexto em discussão.

Podem-se perceber pontos comuns entre as propostas metodológicas de Paulo Freire e os postulados de Emília Ferreiro, Vygotsky e Piaget. Ribeiro e colaboradores (1992) salientam que Ferreiro e Teberosky (1986), mesmo não concordando com a silabação de palavras geradoras, reconhece a necessidade de considerar os conhecimentos que o adulto 
analfabeto tem sobre o sistema de escrita e o método de experiências de linguagem. Já Vigotsky (1984) afirma que o aprendizado advém das experiências vivenciadas, da qualidade de instrução recebida, que tanto pode ser da escola ou de fora dela, e estabelece que o desenvolvimento e a aprendizagem se inter-relacionem. $\mathrm{O}$ construtivismo piagetiano e as ideias de educação transformadora de Paulo Freire têm proximidade, afirma Piconez (2002), por retratarem o sujeito ativo na construção do conhecimento.

As atividades propostas durante a alfabetização do adulto no Círculo de Cultura, com projeção de slides (as chamadas fichas de cultura), podem conter situações problematizadoras através das palavras geradoras (com forte conteúdo social). As diferentes estratégias, como, por exemplo, jogos e recursos alternativos, permitem a participação efetiva do aluno, por escolherem o que querem aprender e escreverem palavras nas lâminas para a projeção.

As fichas podem ser produto da criação dos educadores ou feitas juntamente com eles, construídas pelo grupo; os desenhos sugerem situações concretas da vida e suscitam ideias por meio do debate. A partir daí, podem aparecer palavras que originam outras e, mais adiante, surgem pequenas expressões e, depois, as frases completas. Isso representa a construção e a reconstrução do conhecimento, a todo o momento, em atividades propostas.

Além do já comentado, há, ainda, a questão da motivação, algo muito importante quando se trata de EJA, já que o jovem e o adulto, devido às próprias condições de vida, apresentam baixa autoestima e desânimo, além do cansaço decorrente do trabalho que desempenham. Esses são alguns dos impedimentos para eles perseverarem nos estudos.

A evasão é algo estarrecedor nas salas da EJA. As faltas são frequentes, o que impede o andamento do aprendizado. Por isso, é preciso fazer com que essa clientela escolar entenda a importância e o valor da alfabetização para a satisfação de suas necessidades básicas, ligadas à sobrevivência. Além disso, as diferenças entre as pessoas crescem com a idade; por isso, a educação de adultos deve considerar as diferenças de estilo, tempo, lugar e ritmo de aprendizagem. Ademais, adultos são motivados a aprender à medida que experimentam que suas necessidades e interesses serão satisfeitos. Nesse sentido, a experiência é a mais rica fonte para o adulto aprender e é, consequentemente, o centro da metodologia da educação de jovens e adultos.

É preciso haver significado no que está sendo aprendido pelo alfabetizando. Devese levá-los a essa significação por meio da motivação e da curiosidade, de forma viva e dinâmica, principalmente quando se trata desse público já carregado de experiências decorrentes do contato com o mundo e da necessidade de sobrevivência. Portanto, devese partir do pressuposto de que esses jovens e adultos são portadores de conhecimento prévio.

Ribeiro et al. (1992) argumentam que uma das motivações maiores do adulto em aprender a ler e a escrever é poder assinar o próprio nome, para que possa, assim, ser libertado do estigma de analfabeto. Além disso, a escrita do próprio nome o ajuda a resolver problemas práticos diários que dependem da assinatura.

Freire, como enfatiza Palandré (2002), considera a alfabetização como um ato criador, como um conhecimento que o aprendiz constrói a partir de conteúdos internalizados. Assim, novos conhecimentos vão sendo sistematizados no universo vocabular e no discurso provido da leitura do mundo. A teoria freiriana aponta que

o mais importante não é a atividade de manuscritura, mais sim o desenvolvimento de uma consciência linguística, de apropriação de um conhecimento que possibilite uma leitura crítica do mundo, um compreender-se produto e produtor de cultura. (FREIRE, 1989, p. 104). 
Para Ribeiro et al. (1992, p. 22),

O que caracteriza o enfoque Paulo Freire é principalmente um postulado filosófico e pedagógico, o diálogo, ancorado numa postura política bastante definida: o reconhecimento do alfabetizando adulto como pertencente a um grupo social oprimido. Isso implica no compromisso do educador com a superação dessa opressão, na consideração ao oprimido como sujeito desse processo, na busca de relações mais igualitárias e, principalmente, num conteúdo de crítica a ordem social vigente.

Os autores acrescentam que educadores e educandos ensinam e aprendem juntos por meio do diálogo, pois, no dialogo,

os sujeitos (educadores e educandos) realizam a educação como ato de conhecimento e como ato político na medida em que, imersos na realidade espessa que os envolve, tomamna como desafio, através do exercício de um pensar crítico. (RIBEIRO et al., 1992, p. 50).

O Método Paulo Freire representou e representa um processo de educação do povo com a finalidade de levar o indivíduo à consciência de sua situação vivencial e à participação na sociedade, de forma ativa e crítica.

\section{Considerações finais}

A Educação de Jovens e Adultos é uma modalidade de ensino com características bastante peculiares, razão pela qual são necessários esclarecimentos no que tange à clientela escolar e ao conhecimento da trajetória daqueles que dela fazem parte. Exige uma mudança na visão do ensino e, portanto, de diferenciação de estratégias didáticopedagógicas. Esta pesquisa demonstrou que é possível uma prática diferenciada naEJA, pormeio das propostas metodológicas de Paulo Freire. Freire foi um educador preocupado com a alfabetização na idade adulta e inovou o ensino da leitura e da escrita com um método de educação pautado no diálogo entre educador e educando. Para ele, a educação não deve ser imposta, deve ser construção do conhecimento. Propõe uma educação libertadora e dialógica. Para Freire (1987), os homens se educam num processo interativo, o que não se dá de $A$ para $B$ ou de $A$ sobre $B$, mas de $A$ com $B$, mediatizados pelo mundo.

Na proposta desse educador, o trabalho deve ser colaborativo e realizado no coletivo. A construção do conhecimento parte da realidade local. Assim, toda situação da vida do alfabetizando e assuntos relacionados ao seu cotidiano são elementos explorativos para o sucesso na aprendizagem da língua oral e escrita.

A metodologia direcionada por Paulo Freire oferece um caminho, uma proposta de trabalho de alfabetização, no qual só há sentido quando há compreensão e construção por parte do educando. Nada pode ser imposto e rígido. A educação é percebida como ato político, pois conduz o indivíduo à libertação das forças opressoras que o impedem de ser participativo na sociedade que o determina.

Uma reflexão essencial proporcionada por este estudo é que, para além do ensinar e aprender, do saber da língua oral e escrita, o educador deve ter um compromisso com a educação emancipatória e democrática, para a construção do sujeito ativo, participativo e crítico.

Além disso, o grande desafio é levar os educadores da EJA à formação continuada, para que realizem trabalhos diferenciados, já que a formação de professores, tradicionalmente, não contempla as necessidades específicas desta área educacional, ficando esses profissionais impossibilitados de ter uma percepção real das situações cotidianas, configuradas, hoje, nas ações educativas, não concretizando um direcionamento do ensino e da aprendizagem condizente com a alfabetização do jovem e do adulto. 
Desta feita, este estudo proporcionou a prática pedagógica dos educadores que conhecimentos significativos que nortearão trabalham nesta modalidade de ensino.

\section{Referências}

BRANDÃO, C. R. O que é Método Paulo Freire. São Paulo: Brasiliense, 1981.

FERREIRO, E.; TEBEROSKY, A. A psicogênese da língua escrita. Porto Alegre: Artes médicas, 1986.

FREIRE, P. A importância do ato de ler: em três artigos que se completam. 49. ed. São Paulo: Cortez, 1989.

. Conscientização: teoria e prática da libertação: uma introdução ao pensamento de Paulo Freire. Tradução de Kátia de Mello e Silva. 3. ed. São Paulo: Moraes, 1980.

Pedagogia do oprimido. 17. ed. Rio de Janeiro: Paz e Terra, 1987.

PALANDRÉ, N. L. Ensinar e aprender com Paulo Freire: 40 horas e 40 anos depois. São Paulo: Cortez, 2002. (Biblioteca Freiriana, 2).

PICONEZ, S. C. B. Educação escolar de jovens e adultos. Campinas, São Paulo: Papirus, 2002. (Coleção Papirus Educação).

RIBEIRO, V. M. M. et al. Metodologia de alfabetização: pesquisas em educação de jovens e adultos. Campinas: Papirus, 1992.

VYGOTSKY, L. S. A formação social da mente. São Paulo: Martins Fontes, 1984.

Submetido em 30 de janeiro de 2014.

Aprovado em 6 de março de 2014. 